\title{
A study of methods for evaluating the success of the transition period in early-lactation dairy cows
}

\author{
J. M. Lukas, ${ }^{*}$ J. K. Reneau, ${ }^{* 1}$ R. L. Wallace,† and A. De Vries \\ *Department of Animal Science, University of Minnesota, St. Paul 55108 \\ †Department of Animal Science, University of Illinois, Urbana 61802 \\ ‡Department of Animal Sciences, University of Florida, Gainesville 32611
}

\begin{abstract}
Three transition monitors were developed in this study that serve on 2 levels: the individual cow level and the herd level. On the first level they screen all cows for potential onset of postparturient health disorders and could be used to trigger implementation of more specific diagnostic initiatives. On the second level they can be used within herd to monitor the implementation of transition protocols and evaluate the transition management on the farm, signaling potential problems before clinical disease onset. The performance of 3 transition monitors based on daily milk yield (MY) within the first $7 \mathrm{~d}$ in milk was evaluated in 3 herds with differing transition management intensity. The 3 monitors considered were increase in MY (LINE), average MY (MY7), and the difference between MY7 and expected MY (transition success measure, TSM). Transition monitors were evaluated not only as withinherd predictors of individual cow transition problems but also as indicators of herd transition management failures by relating their value with probability of earlylactation health disorders, culling, and treatment cost. Analysis of logistic models, correlations, and sensitivity and specificity estimates identified TSM as the most reliable measure of transition failure on both the individual cow level as well as the farm level across all study herds, with best performance achieved in herds with the most intensive postpartum cow management. As evaluated by logistic regression models, TSM was able to successfully predict the probability of a cow remaining healthy for the first $21 \mathrm{~d}$ of lactation (c-statistic between 0.68 and 0.78 ), and probability of culling by $100 \mathrm{~d}$ in milk (c-statistic between 0.73 and 0.86 ). Total cost of treatment by $21 \mathrm{~d}$ in milk also showed the strongest correlation with TSM, with correlation coefficients ranging between 0.2 and 0.4. Statistical-process control cumulative sum charts for TSM designed to monitor postpartum management process in the herd identified
\end{abstract}

Received June 24, 2014.

Accepted September 17, 2014.

${ }^{1}$ Corresponding author: renea001@umn.edu transition failure events with at least $90 \%$ sensitivity at specificity above $92 \%$ within a $14-\mathrm{d}$ window of $7 \mathrm{~d}$ before and $7 \mathrm{~d}$ after the event.

Key words: transition management, statistical process control, health monitoring

\section{INTRODUCTION}

The calving period is associated with reduced immune function and feed intake, negative energy balance, and insulin resistance causing 30 to $50 \%$ of the dairy cows to suffer from metabolic or infectious disease during transition (LeBlanc, 2010). Researchers agree that intensive monitoring of fresh-cow health is crucial for further lactational success and have focused considerable research on developing methods of evaluating transition-cow status (LeBlanc, 2010). The main issue in such studies is choosing a performance measure that is strongly related to the physiological balance of the animal (Mertens et al., 2010) and provides information on cow health status as early into the lactation as possible.

Addressing the importance of providing information on the health and disease status of the cow as early as possible (Hachenberg et al., 2007) has led to the introduction of several screening tools such as body condition scoring (Heuer et al., 1999) and blood or urine sampling (LeBlanc, 2010) in the dry period. However, the time lag for blood and urine sampling results, the sampling cost, and increased labor when managing cow testing outside of the milking parlor (Hachenberg et al., 2007) limit routine use of these tests on farm.

Automated sensors detecting health problems in milking cows have been introduced and include milk electroconductivity, milk temperature, activity, and rumen pH meters, to mention a few (Rutten et al., 2013). Individual studies report high sensitivities and specificities of particular sensors. Problems with among-cow and among-farm variability and the choice of the gold standard defining health status persist, whereas uncertain cost-to-benefit ratios of sensor technology question the economic gain of implementation (Rutten et al., 2013). 
Using data that is already available as a prescreening tool to select suspect cows for more definitive diagnostic tests conserves time and financial resources. For example, milk-production data are sensitive to cow physiology, disease status, and management interventions. It has economic value, can be frequently (automatically) collected, and is available on a wide range of dairy farms worldwide. Several studies (Edwards and Tozer, 2004; Lukas et al., 2009) have shown decreased milk production of either sudden or gradual character (Deluyker at al., 1990, 1991) associated with clinical disease symptoms, and Bareille et al. (2003) demonstrated that milk production of cows experiencing clinical signs is compromised from $5 \mathrm{~d}$ preceding disease diagnosis. Daily individual-cow milk-production recording is becoming an industry standard, associated with no additional cost or labor, and is readily available on an increasing number of dairy farms, even those not enrolled in DHIA or other herd testing.

Successful development and implementation of a monitor identifying individual animals with suboptimal performance based on their milk production during the transition period would provide timely feedback for additional diagnostic testing and prevention of further clinical-disease development. Common sense would dictate that the earlier into the dry period or current lactation a monitor is available, the greater its preventive value (LeBlanc, 2010).

This study focused on using the individual cow daily milk yield (MY) in the first week after parturition for monitoring, considering the following 3 measures: rate of increase in MY (LINE), average MY in the first $7 \mathrm{~d}$ (MY7), and the differences between MY7 and expected MY. This difference is referred to as the transition success measure (TSM).

The second purpose of implementing this monitor based on 1 of the 3 measures would be to assess transition management at the herd level. Looking for a way to overcome the inconsistencies in health records within and between farms, Nordlund and Cook (2004) focused on early-lactational performance data as a source of unbiased and standardized information on the transitioncow management program implemented on the farm. Nordlund (2006) used MY and other information gathered during monthly on-farm DHIA testing to develop the Transition Cow Index. He reasoned that dairy farms that engage in routine DHIA testing (around $47 \%$ of US herds; AIPL, 2012) can use the Transition Cow Index to evaluate the general health of fresh cows and observe changes in transition-cow management based on comparisons with peers.

Bach et al. (2008) found significant associations between stall maintenance, stocking rate, and feed push-ups and the average MY recorded for the herd.
Therefore, continuous monitoring and evaluation of the herd-level MY data can bring focus to emerging cow transition-process issues associated with changes in stocking rate, dairy personnel, feed quality, or other potential periparturient stressors. Statistical process control (SPC) is a set of methods that can be applied to continuously evaluate the state of various processes on the farm. Mertens et al. (2010), in a review of SPC methods in livestock production, list 18 studies published in the 8-yr period from 2001 to 2009. Areas associated with reproduction (de Vries and Conlin, 2003), milk quality (Lukas et al., 2005), feed quality (St-Pierre and Cobanov, 2007), water intake, and health management (Lukas et al., 2008; Miekley et al., 2013) have all been monitored using SPC.

Applying SPC to monitor the fresh-cow performance would alert the farm manager of any changes occurring in transition-cow management so that the source of problems can be identified and timely corrective action can be implemented. The goal of such an intervention would be to minimize predisposing stress factors at the onset of lactation that could cause the animals to develop periparturient diseases and forfeit future milk production, and when appropriate management intervention has the greatest potential to positively affect the cows.

The primary objective of the study was to evaluate methods for determining the success of the transition period of individual cows in early lactation. A secondary objective was to evaluate a SPC monitoring method to assess within-herd change in transition-cow management over time, even in herds with limited or no health records.

\section{MATERIALS AND METHODS}

\section{Data}

Herd A. Individual-cow daily (per milking) milkproduction data along with health records were collected from a 230-cow Midwestern freestall and tiestall dairy herd (herd A) between January 2004 and May 2009. A postpartum screening process was implemented from 1 to 14 DIM. Data were available on a daily basis to assess each cow and included MY, MY deviation, feed intake, attitude, rectal temperature, manure consistency, and uterine discharge. If by d 14 all screening parameters were within normal limits, from d 15 to 21 , only MY and feed intake were monitored along with a visual appraisal. Declining MY or abnormal findings triggered a complete physical exam. Case definitions and standardized treatment protocols were established for all common health disorders that afflict dairy cows (Lukas et al., 2009). Treatment protocol development, diagnosis, and treatment applications were conducted 
under the supervision of a single veterinarian for the duration of the study time frame. All diagnoses, treatments, doses, frequencies, and person administering treatment were recorded in cow-monitoring software. All culling decisions were made by the same herd manager, and cows were culled mainly because of low MY, reproductive failure, and high SCC. A total of $77 \%$ of cows culled were culled by 100 DIM, and the calculated herd turnover rate was $16 \%$.

Herd B. Individual-cow daily (per milking) milkproduction data along with health records were collected from a 500-cow Southeastern freestall dairy herd (herd B) between January 2011 and September 2013. At 4, 7, and 12 DIM, each cow was evaluated by farm personnel for MY, attitude, temperature, uterine and udder health, urinary ketones, and rumen activity. Cows with low MY at any given day postpartum were given a complete physical exam. Cows were evaluated, diagnosed, and treated according to the standard operating procedures of the herd. All treatments, doses, frequencies, and person administering treatment were recorded in cow-monitoring software. Cows were culled by the same herd manager, mainly because of a combination of reproductive failure (21\% of all culls), high SCC $(21 \%)$, and low MY (15\%). A total of $40 \%$ of cows culled were culled by 100 DIM, and the herd turnover rate was $18 \%$.

Herd C. Individual-cow daily (per milking) milkproduction data along with health records were collected from a 100-cow upper Midwest tiestall dairy herd (herd C) between December 2008 and November 2013. Postpartum cow management in the herd consisted of a visual observation by the herd's manager of the general attitude, feed intake, and uterine discharge of a cow. When cows were perceived as potentially having a problem, rectal temperatures were taken and appropriate treatment options completed. All treatments administered in the herd were recorded in a dairy-barn $\log$ book by date, cow number, and name of administered medication. Cows were culled mainly because of reproductive failure, followed by clinical-mastitistreatment failure or injury. Milk yield was not used as a criterion for cow removal. A total of $20 \%$ of cows culled were culled by 100 DIM, and the herd turnover rate was $30 \%$.

The cows in all 3 herds were monthly tested by DHIA. Individual-cow DHIA reports from the first test day after calving for the cows in the test samples were obtained and used to describe the performance of sick and healthy cows during transition in the 3 study herds.

For MY performance validation, the presence or absence of diseases was based on herd health records. Disease recording was based on the disease definitions suggested by Kelton et al. (1998) and as used by Lu- kas et al. (2009). A summary of those definitions is provided in Table 1. Each herd's health records were categorized by type into 3 groups (udder, metabolic, other in herd A and herd B) or 2 groups (udder and other in herd C). The health groups were created based on management area of concern, potential effect on MY (Lukas et al., 2009), and available diagnostic information from each herd. The health group udder included udder cleft dermatitis, edema, and mastitis in herd A; mastitis and udder cleft dermatitis in herd B; and mastitis in herd C. Metabolic diseases group encompassed both metabolic and digestive problems and consisted mainly of ketosis, low intake, digestive problems, and milk fever in herd A and moderate to strong ketosis, milk fever, and displaced abomasum in herd B. Other disease group included retained placenta, lameness, and metritis in herd A; metritis, lameness, fever, and respiratory problems in herd $\mathrm{B}$; and fever in herd $\mathrm{C}$.

Each herd was analyzed separately. Missing milkproduction records were interpolated using the SPLINE method of the proc expand procedure of SAS. Cow lactations with more than 2 missed records by 7 DIM or $10 \%$ missing records by 21 DIM were eliminated, leaving 1,510, 1,944, and 344 usable lactations in herds A, B, and C, respectively. Daily milk yield was calculated as the sum of all milkings per day.

The 3 monitors considered were increase in MY (LINE), average MY (MY7), and the differences between MY7 and expected MY (TSM). Calculation of an expected MY for the TSM required a training sample; therefore, MY and health-record data from all herds were divided into 2 parts. Data from cows calving within the first $53 \mathrm{mo}$ of herd A data (January 2004 until April 2008), first 20 mo of herd B data (January 2010 until August 2012), and first 13 mo of herd C data (December 2008 until December 2009) constituted the training samples and were used to develop the TSM. Any results reported in the study are calculated for cows from the test samples, i.e., calving between May 2008 and May 2009 in herd A, September 2012 and September 2013 in herd B, and January 2010 and November 2013 in herd C.

\section{Transition Monitors}

Design. The MY7 of cow in the test samples was calculated as the average daily MY during the first 7 DIM as follows:

$$
\mathrm{MY}_{c}=\frac{\mathrm{MY}_{c \mathrm{~d} 1}+\ldots+\mathrm{MY}_{c \mathrm{~d} 7}}{n},
$$

where $c$ is the cow ID, MY $7_{c \mathrm{~d} 1-7}$ is that cow's daily MY on 1 through 7 DIM, and $n$ is the number of days with 
Table 1. Definition of the most common health disorders diagnosed in the study herd

\begin{tabular}{ll}
\hline Health disorder & Case definition \\
\hline Mild mastitis & Alert, no fever, eating well, abnormal milk \\
Moderate mastitis & Alert, no fever, eating well, abnormal milk, inflamed udder \\
Severe mastitis & Depressed; off feed; decreased milk production; fever; abnormal milk, inflammation, or both \\
Udder edema & Abnormal swelling of udder, cow may also exhibit discomfort in lying or standing position \\
Udder cleft dermatitis & Dermatitis with sebaceous exudate and a foul odor found between the udder halves or the udder \\
& and medial thighs of fresh cows. \\
Ketosis & Decreased appetite with evidence of presence of milk, urine, or breath ketones \\
Displaced abomasum & Decreased appetite accompanied with an audible high-pitched resonance produced by percussion of the \\
(left displaced abomasum) & left abdominal wall \\
Milk fever & Cold ears, gritting teeth, subnormal body temperature, staggering gait, off feed, not chewing cud, down cow \\
& and unable to rise \\
Off feed & Not eating; cow may have enlarged, gas-distended left flank; depressed; kicking at belly; repeatedly rising \\
& and lying down; straining but no feces passed \\
Pneumonia & Excessive coughing; labored breathing, purulent nasal discharge, or both with animals off feed; \\
decreased milk production; fever & Abnormal uterine discharge with bad odor and clinical signs of systemic involvement (off feed, depression, \\
Metritis & fever) \\
Retained placenta & Arched back when standing or walking, reluctant to stand or bear weight on limbs \\
Lameness &
\end{tabular}

available MY. In herd A milk production for milkings on 1 DIM was not recorded; therefore, $n=6$, and in the remaining 2 herds (B and $\mathrm{C}$ ), $n=7$.

To describe the increase in MY during the first 7 DIM, slope and intercept were calculated for each cow in the 3 herds by regressing MY against day in the first week of lactation in the test samples. Slope represents the daily rate of increase, and intercept represents the level of production. To incorporate both intercept and slope into the transition monitor, LINE was calculated as a product of intercept and slope as follows:

$$
\operatorname{LINE}_{c}=\text { slope }_{c} \times \text { intercept }_{c} \text {, }
$$

where $c$ is the cow ID.

Historical data from the training samples were used to calculate the TSM of cows in the test sample based on the expected MY7 (EMY7). To calculate the EMY7 first the total amount of milk produced by 300 DIM (TMY300) was calculated for each lactation of every cow in the training sample. Then the following model was evaluated based on the data in the training samples for each of the herds separately:

$\mathrm{MY}_{c m}=\beta \mathrm{TMY} 300_{c(m-1)}+$ parity $_{m}+$ season $_{n}+\varepsilon_{c m n}$

where $c$ is cow ID, $m$ is current parity $(1,2$, or $3+), n$ is current season of calving, and $\varepsilon$ is the residual error. Calving season had 2 levels. Cool calving season included cows that calved between September and April. Warm-season cows were those that calved between May and August. For each herd, $\beta$ coefficients and coefficients for each parity and season were saved and used to estimate the EMY7 of each cow in the training samples of each herd according to the following formula:

$$
\begin{aligned}
\mathrm{EMY}_{i m}= & \beta_{h} \mathrm{TMY} \mathrm{SO0}_{i(m-1)}+\text { parity }_{m h} \\
& + \text { season }_{n h}+\varepsilon_{i m n h},
\end{aligned}
$$

where $i$ is cow ID, $m$ is current parity, $n$ is current season of calving, $h$ is the herd name, and $\varepsilon$ is the residual error.

For primiparous cows and older cows with no previous lactation history, EMY7 was defined as the average MY7 of healthy cows (no disease diagnosis by 21 DIM) of the same parity and season of calving, from previous year as outlined by the formula below:

$$
\mathrm{EMY}_{i m n k}=\overline{\mathrm{MY}}_{h m n(k-1)},
$$

where $i$ is the cow ID, $m$ is parity, $n$ is the season of calving, $k$ is the year of calving, and $h$ is the herd name. Because of missing information on MY from the previous lactation for a large number of cows in herd C, EMY7 for all cows in the test sample was calculated using Equation 5. For all cows in the test samples, the difference between the MY7 and EMY7 constituted the TSM.

Evaluation. Factorial ANOVA was used to compute and compare least squares means of LINE, MY7, TSM, DHIA test day MY, and milk-composition variables of cows that remained healthy and those diagnosed with different disease groups. Logistic regressions were used to evaluate the risk of culling by 100 DIM and risk of health problem diagnosis by 21 DIM depending on the value of the transition monitors. Models were compared 
by calculating the c-statistic and receiver operating characteristic (ROC) curves for each model in each herd.

The cost of each treatment was calculated as the cost of medication based on current drug prices and did not account for any additional labor or veterinary visits. Displaced-abomasum surgery was the only exception, where the cost of surgery was added to the cost of drugs administered to the cow. The total cost of treatments administered in the first 21 DIM (C21), 100 DIM (C100), and entire lactation $(\mathbf{C L})$ was calculated for each animal in the 3 herds. The values obtained were matched with the values of 3 transition monitors (LINE, MY7, and TSM) of each cow, and the relationship was summarized by Pearson correlation and linear regression.

\section{SPC Charting Scheme to Monitor Herd Performance}

Design. Data from the test samples were used to develop the cumulative sum (CUSUM) charts of LINE, MY7, and TSM. The 3 monitors were observed for decrease in mean or increase in variation. Process mean and standard deviations necessary to develop the charts were continuously updated and calculated based on the LINE, MY7, or TSM values for the last 100 fresh cows. Every time a cow calved, a downward $\left(S^{-}\right)$ CUSUM for mean and upward $\left(V^{+}\right)$for variation were calculated as presented below (Hawkins and Olwell, 1998) and plotted on the CUSUM chart.

$$
\begin{gathered}
S_{n}^{-}=\min \left(0, S_{n-1}^{-}+U_{n}+k_{s}\right), \\
V_{n}^{+}=\max \left(0, V_{n-1}^{+}+W_{n}-k_{v}\right), \\
\text { where } U_{n}=\frac{X_{n}-\bar{X}_{n-1}}{s_{n-1}}, W_{n}=\frac{\sqrt{\left|U_{n}\right|}-0.822}{0.349},
\end{gathered}
$$

and $\bar{X}$ and $s_{n}$ are the running mean and standard deviation of the transition monitor and $2 \times k$ is size of the shift in mean or variation that the CUSUM is optimized to detect. To identify when the shift has occurred a decision interval was plotted on the chart at $h_{v}$ and $-h_{s}$. The $V_{n}^{+}$and $S_{n}^{-}$values outside the decision interval $\left(V_{n}^{+} \geq h_{v}\right.$ or $\left.S_{n}^{-} \leq h_{s}\right)$ were considered out of control. The $h$ value can be obtained from software provided by Hawkins and Olwell (http://www.stat.umn.edu/ cusum/software.htm) by entering chosen $k$ and desired average time to false signal.

Evaluation. A gold standard was developed to evaluate the efficiency of the CUSUM scheme to detect transition-management problems as follows. Every time a cow calved, the average cost of treatment (AC21) and the percentage of cows that remained healthy (PHY) during transition (0 to 21 DIM) among the cows that calved within the last $7 \mathrm{~d}$ was calculated. If less than 3 cows calved within the 7-d period, the period was extended to the last $14 \mathrm{~d}$. Additionally, 1 grand mean $(\bar{x})$ and 1 standard deviation $(\sigma)$ of AC21 and $1 \bar{x}$ and $1 \sigma$ of PHY were calculated for each herd. Whenever PHY $\leq \bar{x}_{\mathrm{PHY}}-\sigma_{\mathrm{PHY}}$ and $\mathrm{AC} 21 \geq \bar{x}_{\mathrm{AC} 21}+$ $\sigma_{\mathrm{AC} 21}$, the herd was considered to have transition-management problems $\left(\mathbf{P}^{+}\right)$, otherwise the herd was considered to have $\mathbf{P}^{-}$- no transition-management-problem status. In herd A because of the great skewness of the PHY distribution, the PHY criterion was changed to PHY $\leq 25 \%$.

To estimate the sensitivity and specificity of transition monitors, true positives (TP), false positives (FP), and false negatives (FN) were determined for each transition monitor separately. If the CUSUM chart signaled within $7 \mathrm{~d}$ before or $7 \mathrm{~d}$ after the herd was in $\mathrm{P}^{+}$ status, a TP was declared. If a CUSUM signaled and the herd was not in $\mathrm{P}^{+}$status within the $7 \mathrm{~d}$ before or $7 \mathrm{~d}$ after the signal, a FP was declared. If a herd was in $\mathrm{P}^{+}$status and no signal was issued within the $7 \mathrm{~d}$ before or $7 \mathrm{~d}$ after, a FN was declared. The number of true negatives (TN) was calculated by subtracting TP, FP, and FN from the number of cows that calved during the monitoring period. Sensitivity (Se) and specificity (Sp) were calculated as follows:

$$
\begin{aligned}
& \mathrm{Se}=\frac{\mathrm{TP}}{\mathrm{TP}+\mathrm{FN}}, \\
& \mathrm{Sp}=\frac{\mathrm{TN}}{\mathrm{TN}+\mathrm{FP}} .
\end{aligned}
$$

\section{RESULTS AND DISCUSSION}

Milk composition in early lactation has been shown to reflect cow energy status and as such is related to transition-disease risk (Toni et al., 2011). Analysis of the effect of different disease categories on milk composition during the DHIA test is presented in Table 2. Only milk fat in cows with other diseases (herd A) and SCC and protein (herd C) in cows with udder problems were significantly different from healthy cows. Apart from 2 instances (herd B, other group and herd C, udder group), MY did not differ significantly between healthy and sick cows. Therefore, overall, the negative effect of disease on MY and milk composition was not manifested during the first DHIA test day in the 3 study herds. One possible reason for these limited 
differences between sick and healthy cows could be that $70 \%$ of transition diseases were diagnosed early, at DIM $<8$ in herds A and B (data not shown). Another possible reason for this observation may be that postponing the first DHIA test of cows experiencing health problems until the next month is practiced, reflected in the tendency of test DIM to be earlier in healthy group than udder cow group (herd A). The effect of clinical disease on MY researched in previous studies (Lukas et al., 2009) lasted from 3 to more than $49 \mathrm{~d}$. By the time the cows were tested by DHIA, some cows might have recovered and the effect of health disorders on their MY and milk composition might have diminished. In herd $\mathrm{C}$, it took twice as long (16 DIM) to diagnose $70 \%$ of transition problems (data not shown), hence the more significant differences in SCC, MY, and protein content of milk from cows with udder problems in that herd.

Table 2 provides a comparison and validation of the transition-management intensity of the 3 herds. Herd A had the highest MY and lowest SCC of healthy cows among the 3 study herds. Also the effect of diseases on MY was least significant. Healthy cows in herd B were tested earlier (17 vs. 19 DIM) and because of the herd location, were subject to a more demanding environment (especially during summer months). These 2 factors might contribute to a slightly lower MY and higher SCC observed during the DHIA tests. Herds A and C shared similar climatic challenges and average DIM at first test of healthy cows. Previous research (Chassagne et al., 2005; Dufour et al., 2011) has indicated that although SCC is a specific measure of udder health, it is also a good general measure of management intensity. In this context herd A can be identified as having a more intense transition-cow management than herd $\mathrm{C}$ (SCC of healthy group was 57 in herd A vs. 173 in herd C, Table 2). This conclusion is also supported by the description of the transition-cow management provided by the dairy managers and summarized in the previous section.

In Table 3, presenting the effect of health status on the value of the transition monitors, significant differences are more predominant and can be observed across the 3 different herds. The transition monitors seem to distinguish between healthy and sick cows most effectively in herd A and least effectively in herd C. Based on the information given in Table 3, we can sum the number of cows in sick groups (udder, metabolic, and other) and divide this by the number of all cows to get an estimate of transition disease prevalence in the 3 herds with values of $0.63,0.46$, and 0.22 for herds $\mathrm{A}, \mathrm{B}$, and $\mathrm{C}$ respectively. These estimates are counterintuitive and could give the opposite impression that herd $\mathrm{C}$ had the healthiest cows postpartum. However, in more intensively managed herds the chance of diag- nosing health problems early is increased, and hence greater transition-disease prevalence may be observed. As mentioned previously, postpartum cows in herds A and B were evaluated daily according to a standardized protocol. Abnormal MY or rectal temperature initiated further examination and final diagnosis. In herd $\mathrm{C}$ initial symptoms of disease might have been missed, and unless the cow exhibited visual signs of health problems, it might be perceived as healthy. Because the transition management differed between herds so may the health-status definition.

In an attempt to further verify the value of transition monitors to predict the health status of a cow during transition, the cost of treatment was correlated with the value of transition monitors (Table 4). The underlying assumption in this analysis was that the more severe the health problem, the longer and more costly the treatment. These results demonstrate the superiority of the TSM transition monitor as a predictor of cow treatment costs during transition (C21, 1 to 21 DIM) based on performance by 7 DIM. Across the 3 herds TSM had the strongest correlation with $\mathrm{C} 21$ of 0.40 , 0.21 , and 0.20 for herd A, B, and C, respectively. This corresponded to a significant $\mathrm{C} 21$ decrease of $\$ 4.00$, $\$ 1.32$, and $\$ 1.40$ for herd A, B, and C, respectively, for every unit increase in TSM when analyzed by regression (analysis not shown). In herd A, C21, C100, and CL were greatest, and the correlation of all 3 transition monitors with $\mathrm{C} 21$ and $\mathrm{C} 100$ was the strongest. Comparison of the $\mathrm{C} 21, \mathrm{C} 100$, and CL within the 3 herds shows that in herd A, $73 \%$ of treatment cost of the entire lactation are incurred in the first 21 DIM, whereas for herds B and C the values are 43 and $32 \%$, respectively. This, again, identifies herd $\mathrm{A}$ as the herd with the most intense transition management and demonstrates that in transition monitors served as better predictors of individual-cow transition problems in the study herd that was more intensively managed.

The c-statistic (Table 5) and ROC curves (Figure 1) of the logistic models predicting disease incidence by 21 DIM further support this finding. The ROC curves are a visual representation of the trade-off between TP and FP rate as the cut-off for positive and negative results is adjusted. The models based on the best predictors have the greatest area under the curve. The c-statistic is a numerical assessment of model performance. A value of 0.5 is as good as a random pick, a value of $>0.70$ is considered acceptable to strong, and above 0.80 is considered strong to very strong. Again best results are achieved in herd A, with TSM being the most reliable and strongest predictor of disease incidence by 21 DIM and culling by 100 DIM (Table 5, Figure 1, and Figure 2). Across all 3 herds, based on the c-statistic and the ROC curves, TSM and MY7 are better predic- 
Table 2. The LSM comparison of the milk yield (MY) and milk composition measured during the first DHIA test of the healthy cows and cows diagnosed with udder, metabolic, or other diseases between 1 and 21 DIM in the test samples of the 3 study herds ${ }^{1}$

\begin{tabular}{|c|c|c|c|c|c|c|c|c|c|c|c|}
\hline \multirow[b]{2}{*}{$\begin{array}{l}\text { DHIA } \\
\text { variable }\end{array}$} & \multicolumn{4}{|c|}{ Herd A } & \multicolumn{4}{|c|}{ Herd B } & \multicolumn{3}{|c|}{ Herd C } \\
\hline & $\begin{array}{l}\text { Healthy } \\
(\mathrm{n}=60)\end{array}$ & $\begin{array}{c}\text { Udder } \\
(\mathrm{n}=42)\end{array}$ & $\begin{array}{c}\text { Metabolic } \\
(\mathrm{n}=26)\end{array}$ & $\begin{array}{c}\text { Other } \\
(\mathrm{n}=22)\end{array}$ & $\begin{array}{c}\text { Healthy } \\
(\mathrm{n}=252)\end{array}$ & $\begin{array}{c}\text { Udder } \\
(\mathrm{n}=26)\end{array}$ & $\begin{array}{c}\text { Metabolic } \\
(\mathrm{n}=46)\end{array}$ & $\begin{array}{c}\text { Other } \\
(\mathrm{n}=98)\end{array}$ & $\begin{array}{l}\text { Healthy } \\
(\mathrm{n}=101)\end{array}$ & $\begin{array}{c}\text { Udder } \\
(\mathrm{n}=5)\end{array}$ & $\begin{array}{c}\text { Other } \\
(\mathrm{n}=22)\end{array}$ \\
\hline \multicolumn{12}{|l|}{ DIM } \\
\hline LSM & 19.5 & $24.9 \dagger$ & 25.1 & 23.6 & 16.9 & 18.1 & 15.8 & 16.9 & 19.1 & 15.6 & 17.9 \\
\hline $\mathrm{SE}$ & 1.4 & 1.6 & 2.1 & 2.3 & 0.5 & 1.5 & 1.2 & 0.8 & 0.9 & 3.8 & 1.8 \\
\hline \multicolumn{12}{|l|}{ MY (kg) } \\
\hline LSM & 39.4 & 33.7 & 36.7 & 38.7 & 37.0 & 33.2 & 37.0 & $28.6^{* *}$ & 27.8 & $19.1^{*}$ & 26.4 \\
\hline $\mathrm{SE}$ & 1.5 & 1.9 & 2.4 & 2.5 & 0.6 & 2.0 & 1.5 & 1.0 & 0.7 & 3.3 & 1.5 \\
\hline \multicolumn{12}{|l|}{ Fat $(\%)$} \\
\hline LSM & 4.60 & 4.20 & 4.58 & $3.86^{*}$ & 3.98 & 3.83 & 4.19 & 4.14 & 3.83 & 4.22 & 3.92 \\
\hline $\mathrm{SE}$ & 0.14 & 0.17 & 0.22 & 0.23 & 0.07 & 0.21 & 0.16 & 0.11 & 0.06 & 0.29 & 0.14 \\
\hline \multicolumn{12}{|c|}{ Protein (\%) } \\
\hline LSM & 3.09 & 2.92 & 3.00 & 2.92 & 3.17 & 3.01 & 3.14 & 3.17 & 3.35 & $3.90 *$ & 3.26 \\
\hline $\mathrm{SE}$ & 0.05 & 0.06 & 0.08 & 0.09 & 0.03 & 0.10 & 0.07 & 0.05 & 0.04 & 0.18 & 0.09 \\
\hline \multicolumn{12}{|c|}{ Fat:protein } \\
\hline LSM & 1.48 & 1.43 & 1.52 & 1.31 & 1.26 & 1.30 & 1.35 & 1.33 & 1.15 & 1.12 & 1.22 \\
\hline $\mathrm{SE}$ & 0.04 & 0.04 & 0.06 & 0.06 & 0.02 & 0.06 & 0.05 & 0.03 & 0.02 & 0.09 & 0.04 \\
\hline \multicolumn{12}{|c|}{$\mathrm{SCC} \times 1,000$} \\
\hline LSM & 57 & 41 & 71 & 59 & 201 & 489 & 328 & 330 & 173 & $4,346^{* * *}$ & 289 \\
\hline $\mathrm{SE}$ & 14 & 15 & 15 & 16 & 45 & 140 & 105 & 73 & 77 & 353 & 168 \\
\hline
\end{tabular}

${ }^{1}$ Number of cows in each group is given in parentheses.

$\dagger,{ }^{* *}, * * *$ Means different from the healthy-cows group indicated by symbols $(\dagger P<0.1 ; * P<0.05 ; * * P<0.01 ; * * * P<0.005)$. Means with no symbol were not significantly different from the healthy-cows group. 
Table 3. The LSM comparison of the 3 transition monitors ${ }^{1}$ (LINE, MY7, and TSM) of the healthy cows and cows diagnosed with udder, metabolic, or other diseases between 1 and 21 DIM in the test samples of the 3 study herds ${ }^{2}$

\begin{tabular}{|c|c|c|c|c|c|c|c|c|c|c|c|}
\hline \multirow[b]{2}{*}{ Monitor } & \multicolumn{4}{|c|}{ Herd A } & \multicolumn{4}{|c|}{ Herd B } & \multicolumn{3}{|c|}{ Herd C } \\
\hline & $\begin{array}{l}\text { Healthy } \\
(\mathrm{n}=91)\end{array}$ & $\begin{array}{c}\text { Udder } \\
(\mathrm{n}=63)\end{array}$ & $\begin{array}{l}\text { Metabolic } \\
(\mathrm{n}=45)\end{array}$ & $\begin{array}{c}\text { Other } \\
(\mathrm{n}=50)\end{array}$ & $\begin{array}{l}\text { Healthy } \\
(\mathrm{n}=308)\end{array}$ & $\begin{array}{c}\text { Udder } \\
(\mathrm{n}=48)\end{array}$ & $\begin{array}{l}\text { Metabolic } \\
(\mathrm{n}=67)\end{array}$ & $\begin{array}{c}\text { Other } \\
(\mathrm{n}=148)\end{array}$ & $\begin{array}{l}\text { Healthy } \\
(\mathrm{n}=123)\end{array}$ & $\begin{array}{c}\text { Udder } \\
(\mathrm{n}=7)\end{array}$ & $\begin{array}{c}\text { Other } \\
(\mathrm{n}=28)\end{array}$ \\
\hline \multicolumn{12}{|c|}{ LINE (kg/d) } \\
\hline LSM & 34.8 & $21.5 \dagger$ & $2.4^{* * *}$ & $9.8^{* * *}$ & 23.0 & $13.9 \dagger$ & 18.3 & $10.1 * * *$ & 22.0 & 25.4 & $13.8^{*}$ \\
\hline $\mathrm{SE}$ & 3.3 & 4.0 & 4.7 & 4.5 & 1.4 & 3.6 & 3.0 & 2.0 & 1.4 & 5.7 & 2.8 \\
\hline \multicolumn{12}{|c|}{ MY7 $(\mathrm{kg} / \mathrm{d})$} \\
\hline LSM & 28.5 & $22.1^{* * *}$ & $20.8^{* * *}$ & $21.2^{* * *}$ & 20.9 & 18.6 & 22.2 & 16. $2^{* * *}$ & 23.1 & 19.9 & $20.0^{\dagger}$ \\
\hline $\mathrm{SE}$ & 0.9 & 1.1 & 1.3 & 1.2 & 0.5 & 1.2 & 0.9 & 0.7 & 0.6 & 2.3 & 1.2 \\
\hline \multicolumn{12}{|c|}{ TSM $(\mathrm{kg} / \mathrm{d})$} \\
\hline LSM & 1.84 & -0.02 & $-6.55^{* * *}$ & $-7.19^{* * *}$ & -2.21 & -4.11 & $-4.76^{*}$ & $-5.78^{* * *}$ & 0.53 & -3.2 & $-3.0^{* *}$ \\
\hline $\mathrm{SE}$ & 0.86 & 1.03 & 1.22 & 1.16 & 0.37 & 0.94 & 0.80 & 0.54 & 0.47 & 1.95 & 0.98 \\
\hline
\end{tabular}

${ }^{1}$ The 3 monitors considered were increase in milk yield (LINE), average milk yield (MY7), and the difference between MY7 and expected milk yield (transition success measure, TSM).

${ }^{2}$ Number of cows in each group is given in parentheses.

$\dagger,{ }^{*},{ }^{*}, * * *$ Means different from the healthy-cows group indicated by symbols $\left(\dagger P<0.1 ; * P<0.05 ; * * P<0.01 ;{ }^{* * *} P<0.005\right)$. Means with no symbol were not significantly different from the healthy-cows group.

Table 4. Estimates of the Pearson coefficients of correlation between the cow cost of treatment ${ }^{1}$ that occurred in the first 21 DIM (C21), in the first 100 DIM (C100), and during the entire lactation (CL) and the 3 transition monitors ${ }^{2}$ (LINE, MY, and TSM) in the test samples of the 3 study herds

\begin{tabular}{|c|c|c|c|c|c|c|c|c|c|}
\hline \multirow[b]{2}{*}{ Item } & \multicolumn{3}{|c|}{ Herd A } & \multicolumn{3}{|c|}{ Herd B } & \multicolumn{3}{|c|}{ Herd C } \\
\hline & C21 $(\$ 43.50)$ & $\mathrm{C} 100(\$ 45.70)$ & CL $(\$ 59.30)$ & C21 $(\$ 14.70)$ & $\mathrm{C} 100(\$ 23.00)$ & CL $(\$ 33.80)$ & $\mathrm{C} 21(\$ 12.50)$ & C100 $(\$ 15.40)$ & CL $(\$ 39.60)$ \\
\hline LINE & $-0.35^{* * *}$ & $-0.37^{* * *}$ & -0.01 & $-0.18^{* * *}$ & $-0.10^{*}$ & -0.09 & -0.13 & -0.01 & 0.06 \\
\hline MY7 & $-0.25^{* * *}$ & $-0.28^{* * *}$ & 0.08 & $-0.13^{* *}$ & -0.06 & -0.02 & $-0.13 \dagger$ & 0.04 & 0.06 \\
\hline TSM & $-0.39 * * *$ & $-0.41^{* * *}$ & -0.14 & $-0.21^{* * *}$ & $-0.16^{* *}$ & $-0.17^{*}$ & $-0.20^{*}$ & -0.06 & 0.02 \\
\hline
\end{tabular}

C) ${ }^{1}$ The average cost of treatment per animal for the first $21 \mathrm{~d}, 100 \mathrm{~d}$, and entire lactation is listed for each herd.

$\stackrel{\frac{}{\Phi}}{\frac{1}{D}} \quad{ }^{2}$ The 3 monitors considered were increase in milk yield (LINE), average milk yield (MY7), and the difference between MY7 and expected milk yield (transition success measure, గ్ర TSM).

$\lesssim \quad \dagger,{ }^{*},{ }^{* *},{ }^{* * *}$ Significance indicated by symbols $\left(\dagger P<0.1 ; * P<0.05 ;{ }^{* *} P<0.01 ;{ }^{* * *} P<0.005\right)$. Coefficients with no symbol were not significantly different from zero. 
tors of disease and culling than LINE (greater $\mathrm{c}$ and area under ROC curve), and based on Table 4, TSM and LINE are better predictors of cost of treatment postpartum (C21) than MY7. Although it is difficult to rank the 3 monitors from best to worst performing, the TSM seems to be the most consistently reliable predictor in all aspects. There is another advantage of TSM associated with its informative value. Reading the TSM of an individual cow, we know if it is performing according to what it is expected to produce $(\mathrm{TSM} \sim 0$ ) or better $(\mathrm{TSM}>0)$ or worse $(\mathrm{TSM}<0)$ than expected. The MY7 and LINE do not provide this information. Another disadvantage of LINE is that its units $\left(\mathrm{kg}^{2} / \mathrm{d}^{2}\right)$ make practical interpretation difficult. The other 2 measures (MY7 and TSM) are expressed in kilograms per day, which makes it easy to read and intuitively understand as a measure of MY.

Once an appropriate monitor is chosen, it is necessary to consider how it will be used and what benefit it provides to the herd manager. Rutten et al. (2013), in a review of sensors aiding health management on the farm, identified 4 levels of health-management support: level 1 -individual cow measurement; level 2-summary or interpretation to provide information about cow status; level 3-integration of information to produce advice; and level 4-farmer or automated decision. The transition monitors in this study are not targeted to detect specific diseases but do provide early warning signals and a performance baseline for which more specific diagnostic initiatives can be triggered early enough to achieve a more positive corrective treatment result. Cut-offs and tests chosen for screening purposes should have high sensitivity so that all potentially diseased animals are subject to further evaluation. Reading from the ROC curves (Figure 1), TSM identifies $90 \%$ of po- tential health problems with a FP rate of at least $50 \%$. This means that at the cut-off securing a $90 \%$ sensitivity, $50 \%$ of cows identified by TSM as potentially at risk of disease will not be diagnosed with health problems within the first 21 DIM. Only clinical disease cases were considered in this study; therefore, it is possible that subclinically infected cows contributed to the FP rate. Using an action or no action approach with a single cut-off would, however, generate too many FP in time, rendering the TSM less effective. Logistic modeling of the probability of health problems and culling and TSM correlation with future treatment costs allow for associating a specific risk and dollar value to the value of transition monitoring. This allows for interpretation of the TSM depending on management intensity and accommodates both the automated as well as farmer decision making. Intervention should depend on the risk and cost associated with the TSM value of a cow. At the level of integrating economic information and final decision making, the transition monitors can offer potential benefit.

An SPC CUSUM charting scheme was developed as a way to monitor and assess the postpartum management process at the herd level, the second purpose of the transition monitor. To evaluate the performance of SPC monitoring scheme, it was necessary to identify day of transition management failure $\left(\mathrm{P}^{+}\right)$in the test samples of the study herds. The goal of periparturient cow management is to prevent disease and minimize the need for treatment in the postpartum cow. As described in the previous section, 2 criteria were used to establish the gold standard of management failure: percentage of cows that remained healthy postpartum (by 21 DIM) and average cost of treatment by 21 DIM within the group of cows that calved within the last 7

Table 5. The measure of logistic regression fit (c-statistic) for models predicting the disease by 21 DIM or culling by 100 DIM in the test samples of the 3 study herds based on the 3 transition monitors ${ }^{1}$ (LINE, MY7, and TSM) ${ }^{2}$

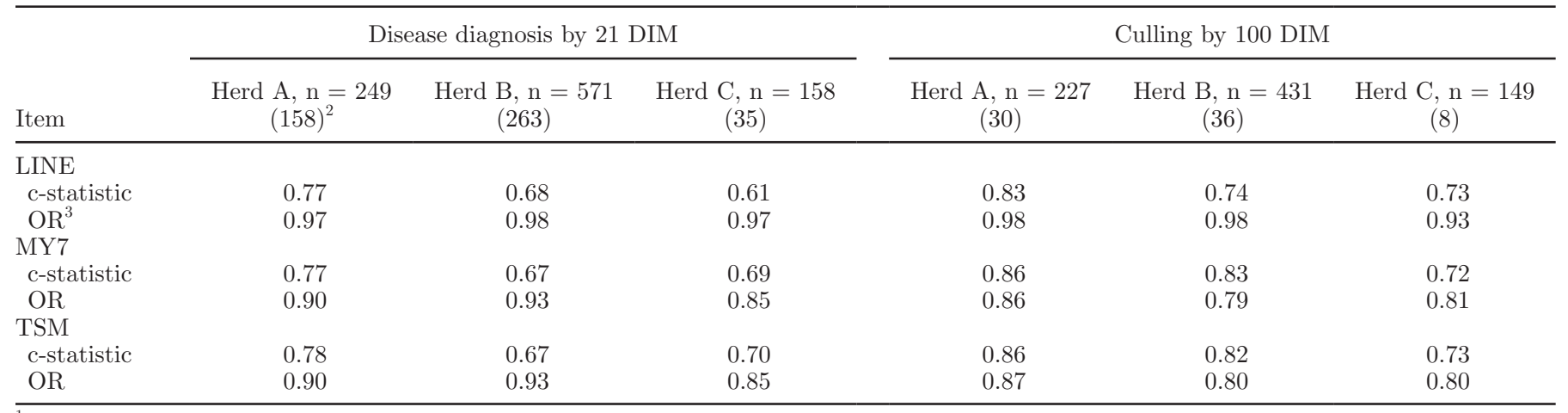

${ }^{1}$ The 3 monitors considered were increase in milk yield (LINE), average milk yield (MY7), and the difference between MY7 and expected milk yield (transition success measure, TSM).

${ }^{2}$ Number of cows included in analysis is listed for each herd; number of sick or culled animals is given in parentheses.

${ }^{3}$ Corresponding odds ratios (OR) for 1-unit increase in transition monitor indicated under each c-statistic. All OR were significantly different from one at the $P<0.05$ significance level. 
A

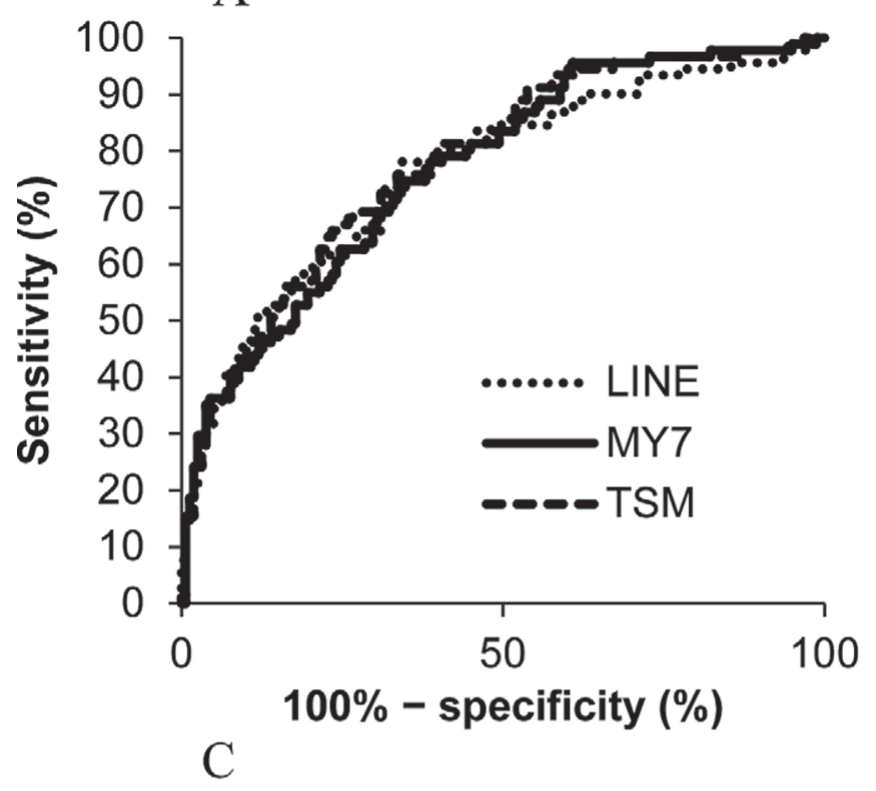

$\mathrm{B}$

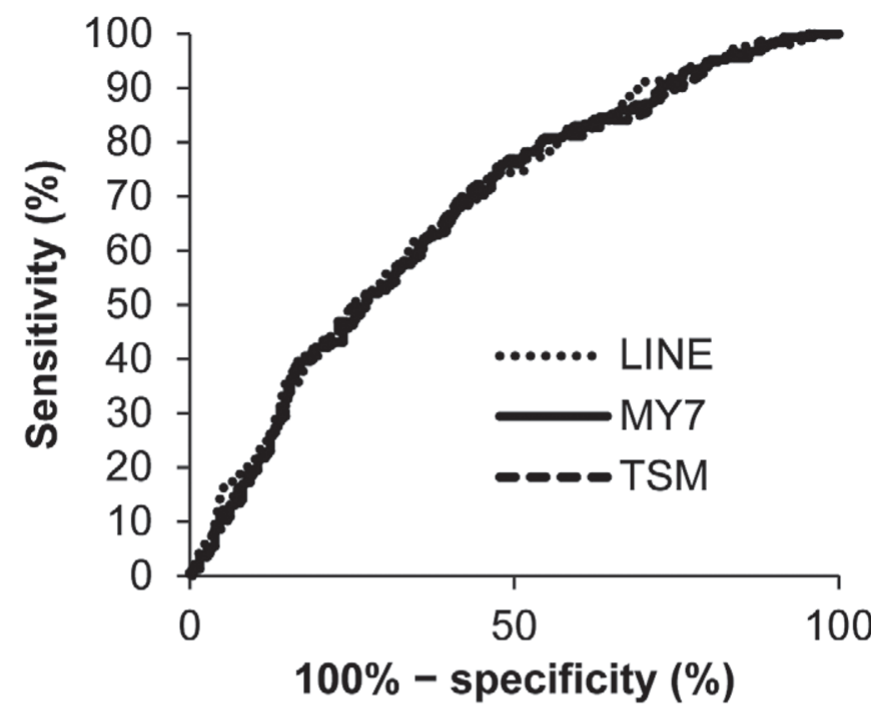

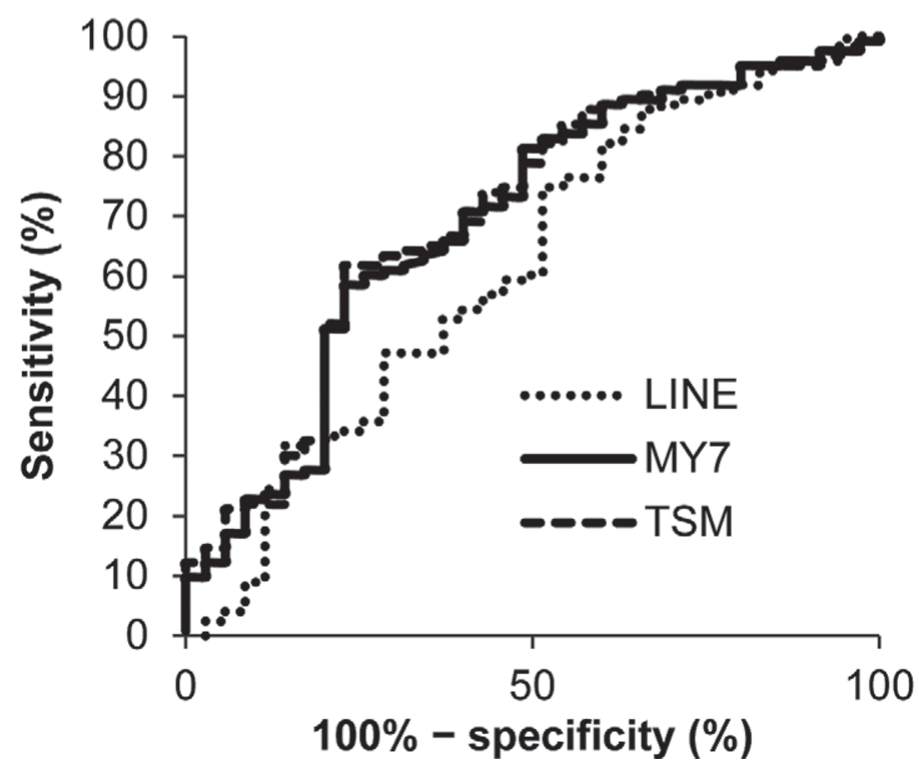

Figure 1. Receiver operating curves of the 3 transition monitors (LINE, MY7, and TSM) as predictors of disease diagnosis by 21 DIM in the test samples of herd A (A), herd B (B), and herd C (C). Sensitivity is plotted on the vertical axis, and 1 - specificity is plotted on the horizontal axis. The 3 monitors considered were increase in milk yield (LINE), average milk yield (MY7), and the difference between MY7 and expected milk yield (transition success measure, TSM).

d. When both of these measures took extreme values, a $\mathrm{P}^{+}$was declared. The extreme values chosen as cut-offs for $\mathrm{P}^{+}$declaration were herd specific, based on mean and deviation in PHY and $\mathrm{AC} 21$ of an individual herd. This approach addressed the previously discussed issue of between-herd variations in management intensity. In practical application the cut-off between transition success and failure would be established by the dairy manager himself depending on his specific management goals. Therefore, the transition monitor would be used only within herd and not as between-herd comparison of management efficiency.

The transition monitor CUSUM chart was successful at identifying $\mathrm{P}^{+}$when it signaled within $7 \mathrm{~d}$ before to 7 $\mathrm{d}$ after $\mathrm{P}^{+}$. Based on these assumptions, sensitivity and specificity were evaluated. The CUSUM charts were designed to maximize sensitivity with specificity above $90 \%$, with $k$ ranging from 0.5 to 0.75 and $h$ between 1.6 and 2.8. Sensitivity and specificity estimates presented in Table 6 clearly identify TSM as the most reliable 

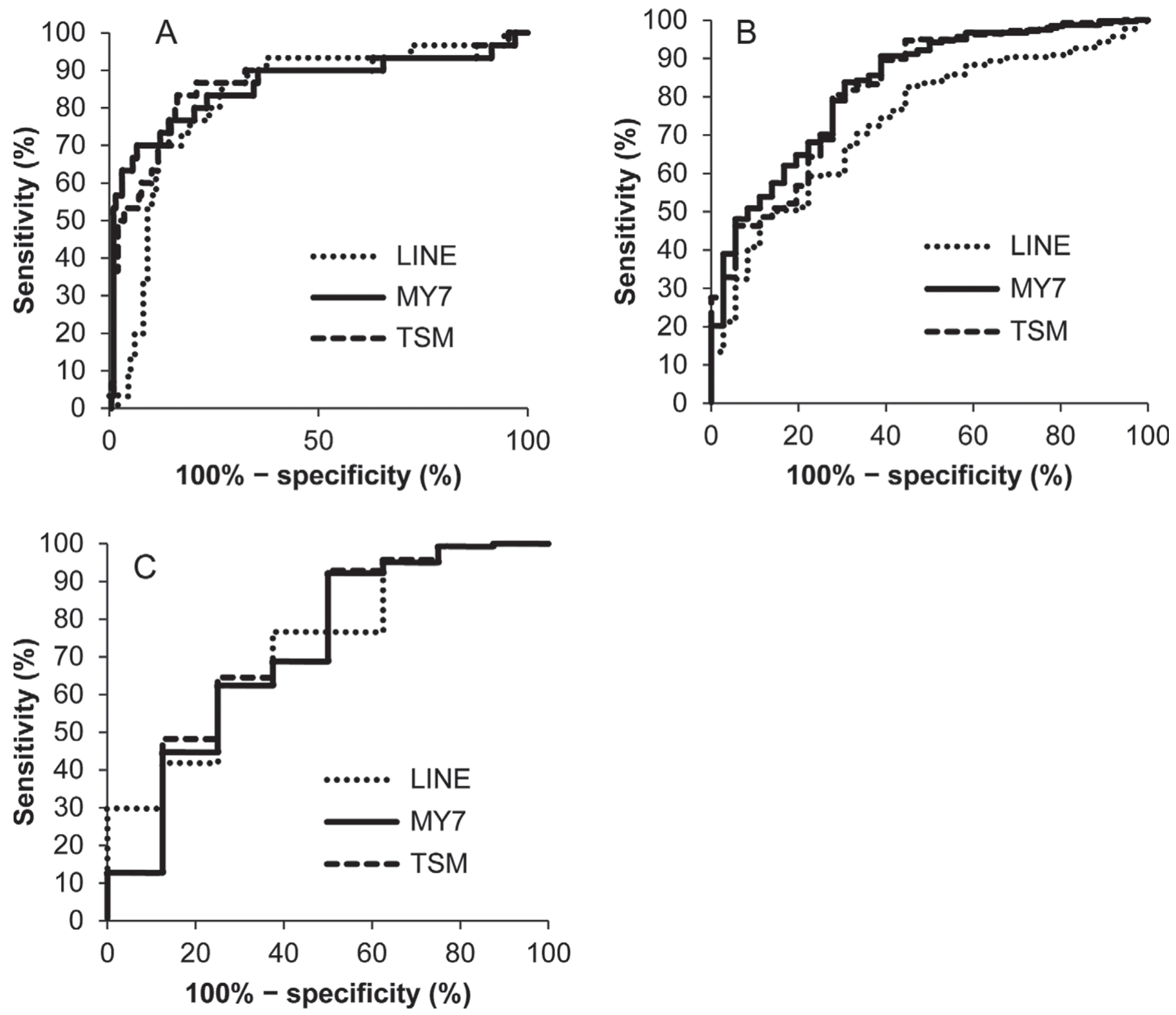

Figure 2. Receiver operating curves of the 3 transition monitors (LINE, MY7, and TSM) as predictors of culling by 100 DIM in the test samples of herd A (A), herd B (B), and herd C (C). Sensitivity is plotted on the vertical axis, and 1 - specificity is plotted on the horizontal axis. The 3 monitors considered were increase in milk yield (LINE), average milk yield (MY7), and the difference between MY7 and expected milk yield (transition success measure, TSM).

predictor of $\mathrm{P}^{+}$across all the 3 herds. The CUSUM charts seem to be performing best, almost perfectly in herd C. These estimates, however, are based on a fraction of the number of calvings available in herds $\mathrm{A}$ and $\mathrm{B}$ and should be interpreted with caution.

To illustrate, a plot of PHY and AC21 of cows calving between December 3, 2008, and January 28, 2009, in herd A is presented in Figure 3A. On January 23, 2009, when both transition-management measures took extreme values $(\mathrm{PHY}=25 \%$ and $\mathrm{AC} 21=\$ 107)$, a transition failure $\left(\mathrm{P}^{+}\right)$was declared (marked by filled squares on the plot). Figure $3 \mathrm{~B}$ is an SPC chart plotted for the same time period. The CUSUM presented in Figure 3B checks for an increase in variation or decrease in mean of the TSM monitor. Increase in variation is a sign of the lack of consistency in the factors affecting the cows during transition and could be, for example, the result of problems with transition protocol implementation by a new employee or inconsistent feed delivery. A drop in mean suggests that conditions before or after calving have become consistently worse because of, for example, increased stocking rate in a fresh pen or change in for- 
Table 6. Sensitivity (Se) and specificity (Sp) estimates of the cumulative-sum-chart scheme monitoring transition-process failure in the test samples of the 3 study herds based on transition monitors ${ }^{1}$ (LINE, MY7, and TSM) $)^{2}$

\begin{tabular}{|c|c|c|c|c|c|c|}
\hline \multirow[b]{2}{*}{ Item } & \multicolumn{2}{|c|}{ Herd A $\left(\mathrm{P}^{+}=21, \mathrm{n}=244\right)^{1}$} & \multicolumn{2}{|c|}{ Herd $\mathrm{B}\left(\mathrm{P}^{+}=32, \mathrm{n}=563\right)$} & \multicolumn{2}{|c|}{ Herd $\mathrm{C}\left(\mathrm{P}^{+}=6, \mathrm{n}=58\right)$} \\
\hline & Se $(\%)$ & Sp (\%) & Se $(\%)$ & Sp (\%) & Se $(\%)$ & Sp (\%) \\
\hline LINE & 47.6 & 92.8 & 53.1 & 95.1 & 100.0 & 100.0 \\
\hline MY7 & 42.9 & 91.9 & 25.0 & 90.2 & 100.0 & 96.2 \\
\hline TSM & 95.2 & 92.8 & 90.6 & 93.0 & 100.0 & 100.0 \\
\hline
\end{tabular}

${ }^{1}$ The 3 monitors considered were increase in milk yield (LINE), average milk yield (MY7), and the difference between MY7 and expected milk yield (transition success measure, TSM).

${ }^{2}$ Number of transition failures $\left(\mathrm{P}^{+}\right)$and number of all calvings (n) used to estimate Se and $\mathrm{Sp}$ in each herd are reported in parentheses.

age quality. Signals marked by empty squares in Figure 3B (on January 8, 2009, and January 10, 2009) are not associated with any management failure on Figure 3A and represent 2 FP. Signals marked by filled squares (18-27 of January 2009, Figure 3B) are issued within 5 $\mathrm{d}$ before and $4 \mathrm{~d}$ after the $\mathrm{P}^{+}$(January 23, 2009, Figure $3 \mathrm{~A})$ and are identified as $1 \mathrm{TP}$.

Specificity of $92 \%$ in a 500-cow herd corresponds to $40 \mathrm{FP}$ signals per year. Therefore, a signal on the CUSUM chart cannot serve as a single diagnostic of management problems. Rather, it should be the action point criterion for implementing specific protocols or management checklist.

\section{CONCLUSIONS}

Transition monitors offer the possibility of identifying cows experiencing problems postpartum earlier, at 7 DIM, giving the herd manager the opportunity for proactive investigation and timely preventive action. Preliminary analysis favors TSM, which seems to be the most consistent reliable predictor in all aspects. The TSM is strongly correlated to the probability of health problems, culling by 100 DIM, and cost of treatment incurred in the first $21 \mathrm{~d}$ of lactation. In addition, the TSM provides information on whether the cow is producing according to expectations. Because TSM is apparently more reliable and of greater informative value, the authors favored using the TSM for overall individual-cow and herd-level monitoring. It is possible that ranking cows according to the TSM with associated probability of health problems, probability of culling, and probable cost of treatments would concentrate the herd manager's attention on cows that are at the greatest risk of experiencing transition problems. This would thereby allow management to introduce new procedures and interventions according to the risk-management policy of the herd. Monitoring TSM by the SPC CUSUM scheme proposed in this study successfully identified transition management failure at the herd level. The CUSUM chart can be sensitized to identify specific changes in TSM. The choice of how sensitive the CUSUM chart should be should be left to the manager, accommodating a wider range of management styles.
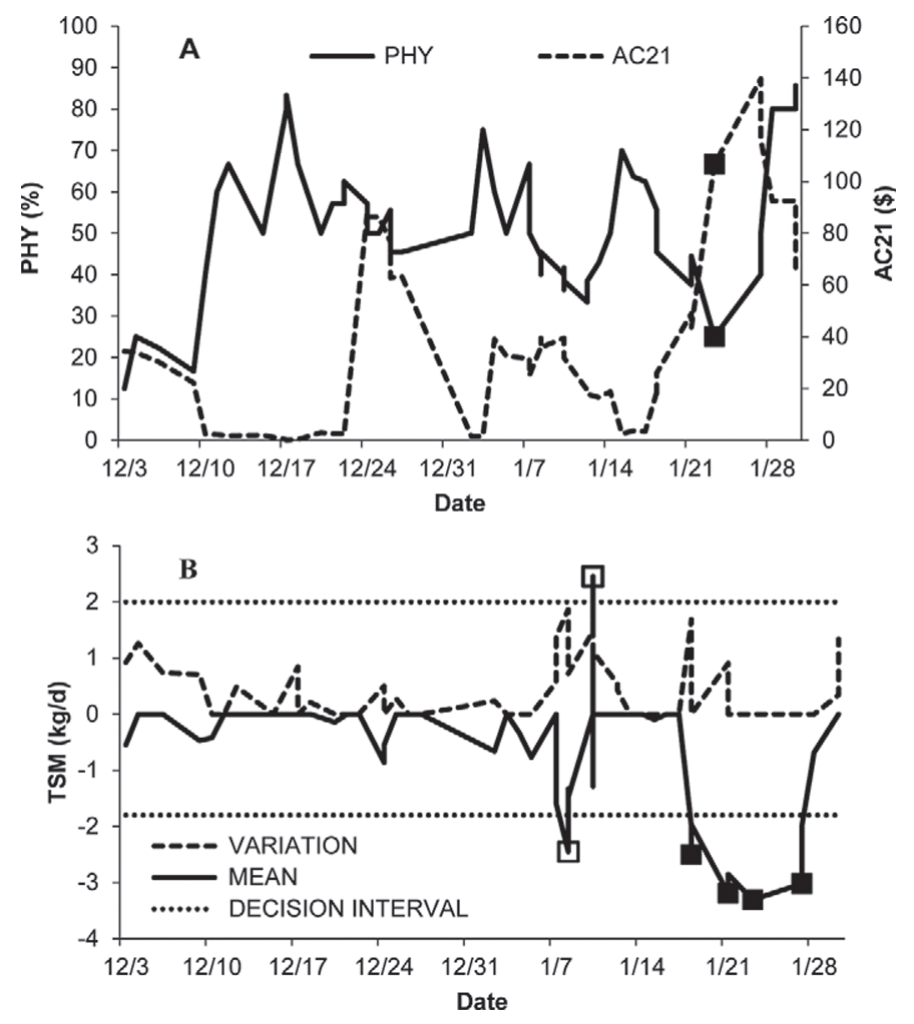

Figure 3. (A) Plot of percentage of cows healthy (PHY) and average cost of treatment by 21 DIM (AC21) in herd A. Transition management failure marked by filled square. (B) Corresponding cumulative sum chart (CUSUM) of transition success measure (TSM) mean and TSM variation. Data points outside of the decision interval are marked by squares. False positive signals on the CUSUM chart are marked by empty squares and correspond to 2 false positives. Signals associated with herd transition failure are marked by filled squares and correspond to 1 true positive. Date $=$ month/day. 


\section{REFERENCES}

Animal Improvement Programs Laboratory. 2012. DHI participation as of January 1, 2012. (DHI Report K-1). Accessed Dec. 11, 2012. http://aipl.arsusda.gov/publish/dhi/current/partall.html.

Bach, A., N. Valls, A. Solans, and T. Torrent. 2008. Associations between nondietary factors and dairy herd performance. J. Dairy Sci. 91:3259-3267.

Bareille, N., F. Beaudeau, S. Billon, A. Robert, and P. Faverdin. 2003. Effects of health disorders on feed intake and milk production in dairy cows. Livest. Prod. Sci. 83:53-62.

Chassagne, M., J. Barnouin, and M. Le Guenic. 2005. Expert assessment study of milking and hygiene practices characterizing very low somatic cell score herds in France. J. Dairy Sci. 88:1909-1916.

de Vries, A., and B. J. Conlin. 2003. Design and performance of statistical process control charts applied to estrous detection efficiency. J. Dairy Sci. 86:1970-1984.

Deluyker, H. A., J. M. Gay, L. D. Weaver, and A. S. Azari. 1991. Change of milk yield with clinical diseases for a high producing dairy herd. J. Dairy Sci. 74:436-445.

Deluyker, H. A., R. H. Shumway, W. E. Wecker, A. S. Azari, and L. D. Weaver. 1990. Modeling daily milk yield in Holstein cows using time series analysis. J. Dairy Sci. 73:539-548.

Dufour, S., A. Fréchette, H. W. Barkema, A. Mussell, and D. T. Scholl. 2011. Invited review: Effect of udder health management practices on herd somatic cell count. J. Dairy Sci. 94:563-579.

Edwards, J. L., and P. R. Tozer. 2004. Using activity and milk yield as predictors of fresh cow disorders. J. Dairy Sci. 87:524-531.

Hachenberg, S., C. Weinkauf, S. Hiss, and H. Sauerwein. 2007. Evaluation of classification modes potentially suitable to identify metabolic stress in healthy dairy cows during the peripartal period. J. Anim. Sci. 85:1923-1932.

Hawkins, D. M., and D. H. Olwell. 1998. Cumulative Sum Charts and Charting for Quality Improvement. Springer-Verlag, New York, NY.

Heuer, C., Y. H. Schukken, and P. Dobbelaar. 1999. Postpartum body condition score and results from the first test day milk as predictors of disease, fertility, yield, and culling in commercial dairy herds. J. Dairy Sci. 82:295-304.
Kelton, D. F., K. D. Lissemore, and R. E. Martin. 1998. Recommendations for recording and calculating the incidence of selected clinical diseases of dairy cattle. J. Dairy Sci. 81:2502-2509.

LeBlanc, S. 2010. Monitoring metabolic health of dairy cattle in the transition period. J. Reprod. Dev. 56(Suppl.):S29-S35.

Lukas, J. M., D. M. Hawkins, M. L. Kinsel, and J. K. Reneau. 2005. Bulk tank somatic cell counts analyzed by statistical process control tools to identify and monitor subclinical mastitis incidence. J Dairy Sci. 88:3944-3952.

Lukas, J. M., J. K. Reneau, and J. G. Linn. 2008. Water intake and dry matter intake changes as a feeding management tool and indicator of health and estrus status in dairy cows. J. Dairy Sci. 91:3385-3394.

Lukas, J. M., J. K. Reneau, R. Wallace, D. Hawkins, and C. MunozZanzi. 2009. A novel method of analyzing daily milk production and electrical conductivity to predict disease onset. J. Dairy Sci. 92:5964-5976

Mertens, K., E. Decuypere, J. De Baerdemaeker, and B. De Ketelaere. 2010. Statistical control charts as a support tool for the management of livestock production. J. Agric. Sci. 149:369-384.

Miekley, B., E. Stamer, I. Traulsen, and J. Krieter. 2013. Implementation of multivariate cumulative sum control charts in mastitis and lameness monitoring. J. Dairy Sci. 96:5723-5733.

Nordlund, K. V. 2006. Transition Cow Index ${ }^{\mathrm{TM}}$. Proc. Am. Assoc. Bov. Pract. 39:139-143.

Nordlund, K. V., and N. B. Cook. 2004. Using herd records to monitor transition cow survival, productivity, and health. Vet. Clin. North Am. Food Anim. Pract. 20:627-649.

Rutten, C. J., A. G. J. Velthuis, W. Steeneveld, and H. Hogeveen 2013. Invited review: Sensors to support health management on dairy farms. J. Dairy Sci. 96:1928-1952.

St-Pierre, N. R., and B. Cobanov. 2007. Optimal sampling schedule of diet components: Model robustness to departure from assumptions. J. Dairy Sci. 90:5395-5404.

Toni, F., L. Vincenti, L. Grigoletto, A. Ricci, and Y. H. Schukken. 2011. Early lactation ratio of fat and protein percentage in milk is associated with health, milk production, and survival. J. Dairy Sci. 94:1772-1783. 